\title{
Rescue endoscopic therapy after malfunctioning choledochoduodenostomy in patient with malignant distal biliary obstruction
}

Endoscopic ultrasound-guided choledochoduodenostomy (EUS-CD) using a lumen-apposing metal stent (LAMS) has recently been reported as an alternative approach after failure of endoscopic retrograde cholangiopancreatography (ERCP) in patients with malignant obstructive jaundice [1].

Here, we report the case of an 83-yearold man affected by obstructive jaundice (total bilirubin $25 \mathrm{mg} / \mathrm{dL}$, predominantly direct) due to advanced pancreatic head cancer with gallbladder in situ. He underwent ERCP; however, it was not possible to cannulate the common bile duct (CBD) because of serrated stenosis, and therefore EUS-CD was performed.

From the duodenal bulb view, the CBD had a diameter of about $20 \mathrm{~mm}$ above the pancreatic mass, and no interposing vessels on Doppler flow were present. An $8 \times 8 \mathrm{~mm}$ LAMS (Hot Axios; Boston Scientific, Marlborough, Massachusetts, USA) was directly deployed, creating an EUS-CD with initial good biliary drainage into the duodenum.

A computed tomography scan confirmed the correct positioning of the stent, which, together with subsequent decompression of the $\mathrm{CBD}$, resulted in improvement in cholestasis parameters. Nevertheless, 2 days later, obstructive jaundice worsened.

Cholangiography with sphincterotome through the LAMS revealed CBD decompression and the LAMS distal flange located close to the contralateral CBD wall, hampering biliary drainage. A $10 \times$ $40 \mathrm{~mm}$ uncovered self-expandable metal stent (SEMS; Wallflex; Boston Scientific) was placed inside the LAMS with its proximal edge in the common hepatic duct, restoring a functional axis, and allowing biliary drainage ( $>$ Fig. 1, $>$ Video 1 ).

The patient remained in a satisfactory clinical condition with progressive resolution of obstructive jaundice and was referred for outpatient oncologic treatment. After 4 weeks of follow-up, labora-

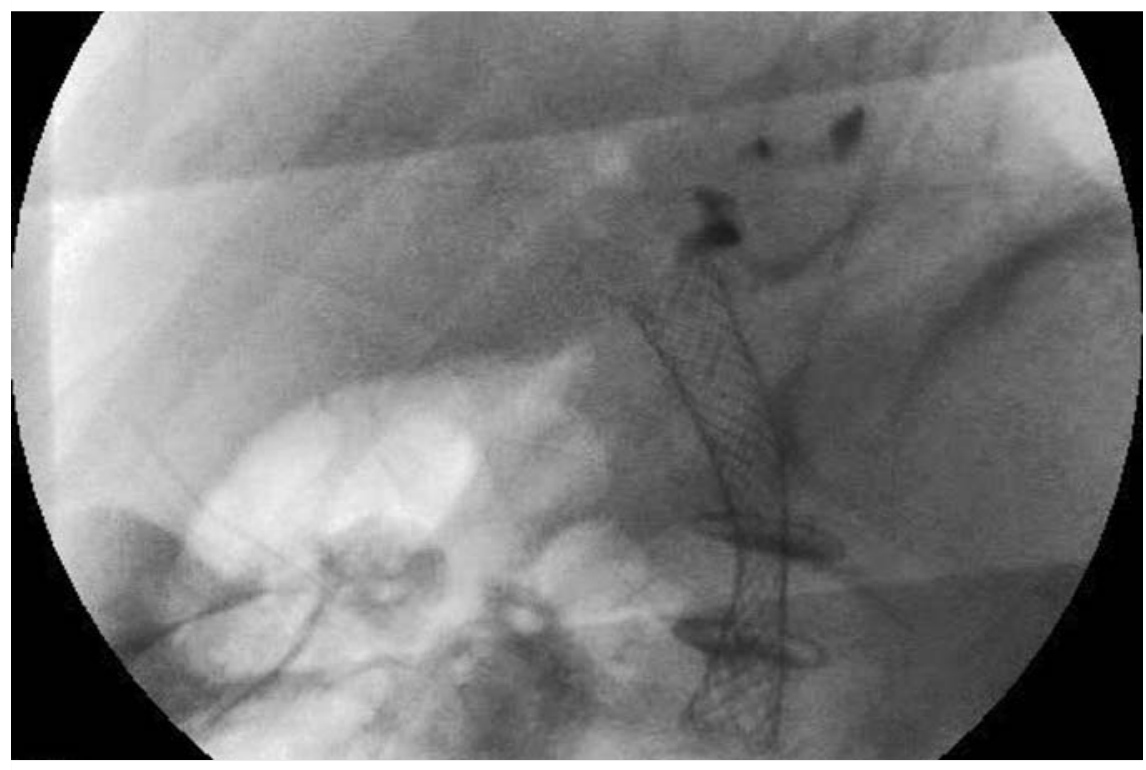

Fig. 1 Fluoroscopic image showing complete biliary drainage after self-expandable metal stent placement inside the lumen-apposing metal stent.
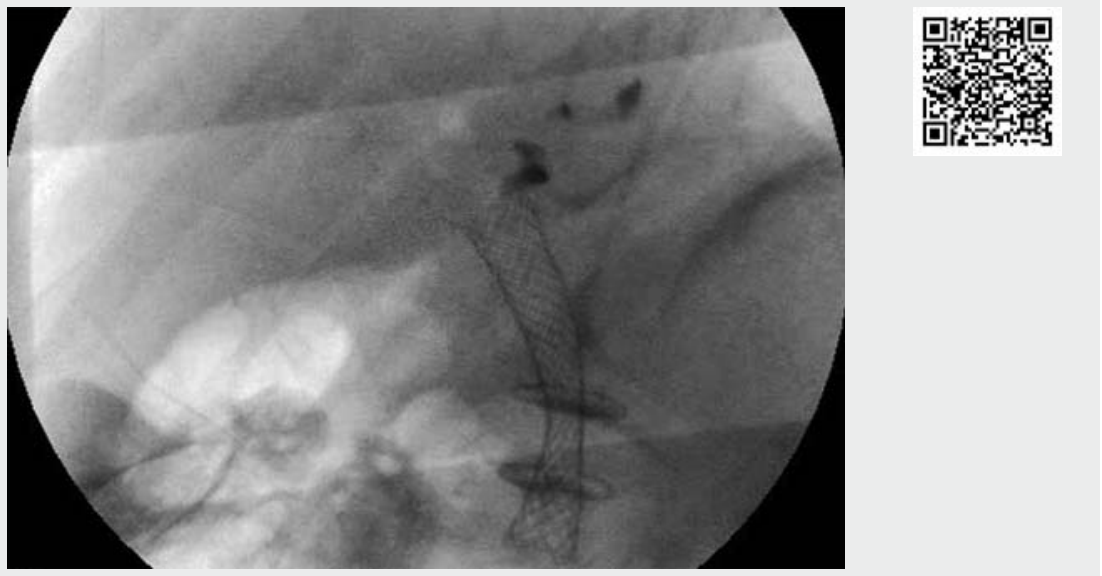

Video 1 Rescue endoscopic therapy - self-expandable metal stent placement inside the lumen-apposing metal stent - after malfunctioning choledochoduodenostomy in a patient with malignant distal biliary obstruction.

tory tests revealed that total bilirubin levels had returned to normal $(1.2 \mathrm{mg} / \mathrm{dL})$. In conclusion, the "SEMS in LAMS technique" can be considered as rescue therapy after malfunctioning EUS-CD. Placement of the uncovered SEMS within the
LAMS restored the functional axis, thus avoiding both risk of stent misplacement and cholecystitis.

Endoscopy_UCTN_Code_TTT_1AS_2AG FB 
None

The authors

Mauro Manno, Sara Vavassori, Simona

Deiana, Laura Ottaviani, Tommaso Gabbani,

\section{Paola Soriani}

Gastroenterology and Digestive Endoscopy Unit,

Azienda USL Modena, Modena, Italy

\section{Corresponding author}

Mauro Manno, MD

Gastroenterology and Digestive Endoscopy Unit, Azienda USL Modena, Via G. Molinari 2, 41120 Carpi, Modena, Italy

Fax: +39-059-650250

m.manno@ausl.mo.it
[1] Anderloni A, Fugazza A, Troncone E et al. Single-stage EUS-guided choledochoduodenostomy using a lumen-apposing metal stent for malignant distal biliary obstruction. Gastrointest Endosc 2019; 89: 69-76

\section{Bibliography}

DOI https://doi.org/10.1055/a-1032-8218

Published online: 7.11.2019

Endoscopy 2020; 52: E144-E145

(c) Georg Thieme Verlag KG

Stuttgart · New York

ISSN 0013-726X

\section{ENDOSCOPY E-VIDEOS}

https://eref.thieme.de/e-videos

口近 Endoscopy E-Videos is a free access online section, reporting 回舴: on interesting cases and new techniques in gastroenterological endoscopy. All papers include a high quality video and all contributions are freely accessible online.

This section has its own submission website at

https://mc.manuscriptcentral.com/e-videos 